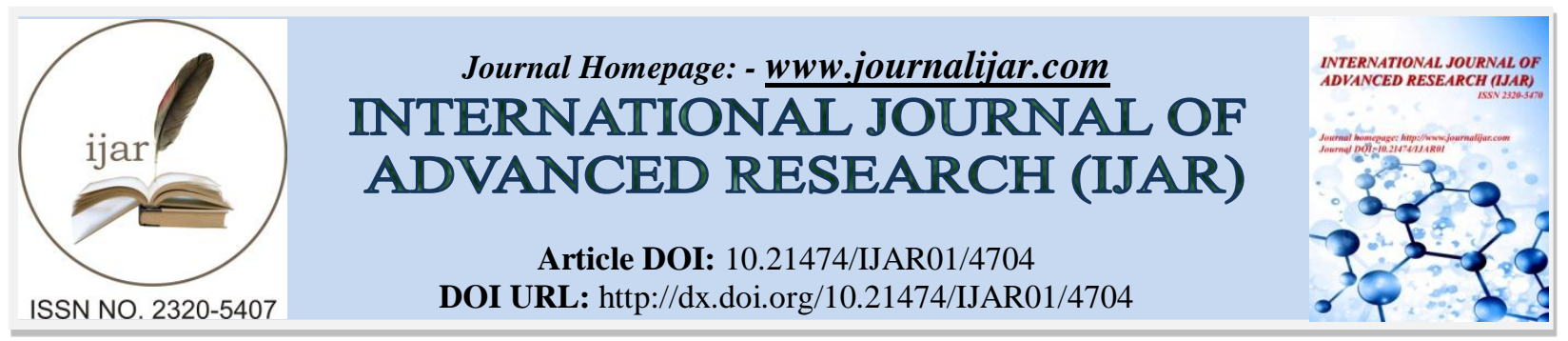

RESEARCH ARTICLE

\title{
SCORING SYSTEM FOR PREDICTING RISK FACTORS FOR DIFFICULT LAPAROSCOPIC CHOLECYSTECTOMY.
}

\author{
Dr. Dhea M. Sh. Ahmad, C.A.B.S.
}

Al-Fallouja Teaching Hospital, Al-Fallouja, Iraq.

\section{Manuscript Info}

\section{Manuscript History}

Received: 2 May 2017

Final Accepted: 4 June 2017

Published: July 2017

Key words:-

Cholelithiasis; gall bladder; laparoscopic

cholecystectomy; open Cholecystectomy

\section{Abstract}

Laparoscopic cholecystectomy proved to be the gold standard in the treatment of cholelithiasis and is replacing open cholecystectomy. The rate of conversion from laparoscopic cholecystectomy to open cholecystectomy range from 5-10\%, that's why it is necessary to study the predictive factors for difficult laparoscopic cholecystectomy. 115 patients were all subjected to ultrasonographic examination. The patients confirmed by US examination are evaluated with following factors: age, sex, BMI, h/o previous hospitalization, h/o previous abdominal surgeries, $\mathrm{h} / \mathrm{o}$ acute cholecystitis. Ultrasonographic findings were Gall bladder wall thickness (> or $<4 \mathrm{~mm}$ ), pericholecystic fluid collection, number (solitary versus multiple) and liver texture (normal, fatty infiltration or fibrosis). Following evaluation the patients were subjected to laparoscopic cholecystectomy and the following operative parameters were assessed: access to peritoneal cavity (easy, difficult), bleeding during surgery (normal, abnormal), gall bladder bed dissection (easy, difficult), injury to duct/artery, and conversion to open surgery. In the present study, BMI > 30, history of cholecystitis, gall bladder wall thickness >4mm, palpable gall bladder, pericholecystic fluid collection, impacted stone were significant predictive factors for difficult laparoscopic cholecystectomy .

Copy Right, IJAR, 2017,. All rights reserved.

\section{Introduction:-}

Laparoscopic cholecystectomy has gradually replaced open cholecystectomy in treatment of symptomatic gall stone diseases. Better cosmesis, short hospital stay, early recovery and return to work and physical activity, all has led to the popularity of this technique, making it the gold standard for the treatment of cholelithiasis (1)

Previously, patient with acute cholecystitis, empyema, gangrenous gall bladder, cirrhotic liver and Mirrizi's syndrome were contraindications for LC, due to the high rate of complications and conversion rate to open $(2,3)$.

With the increament of experience and technology improvement, difficult gall bladder being subsequently dealt with. However, the experience in lap technique, skills of the surgeon, thorough knowledge of risk factors are all important for a safe result. Even though a laparoscopic surgeon should have low threshold for conversion to open technique. In difficult cases, conversion rate of 1.5-19\% have been reported in different published series (4). 
The difficult GB surgery is the most difficult laparoscopic surgery done by general surgeons all over the world and the potential one that put the patient at high risk.

It is integral to know the different clinical, radiological parameters and specific predictors that give some anticipation for lap. chole difficulty which helps in both patient councelling and the surgeon to have better preparation for intra-operative difficulties to be dealt with. Lap. chole. is associated with less morbidity if performed successfully irrespective of the surgery time (5)

Several studies had been carried out to assess the risk of conversion preoperatively. In a study done kama et al,(6) six parameters with-hold namely male sex, upper abdominal tenderness at the time of surgery, previous upper abdominal surgery, ultrasound examination ascertained thick GB wall, age more than 60 years and preoperative diagnosis of acute cholecystitis, were found to have significant effect on the risk of conversion on multirate analysis. According to another similar study by Lee et al. (7), the risk factors for conversion included, age more than 65 years, male sex, patient with previous upper abdominal surgery and a documented history of acute cholecystitis. For that pre-operative prediction of risk of conversion or difficulty of operation is an important aspect of planning laparoscopic surgery. Different scoring systems have been suggested from time to time using different criteria, further adding to the controversy. The following study planned keeping in mind the basic knowledge of inabilities of prediction on the operative table (1) due to certain difficult situation arising during lap. Cholecystectomy. My study aim to pre-operative score to predict the difficulty of lap. Chole.

\section{Materials and Methods:-}

This study was conducted at department of general surgery at All-Fallouja Teaching Hospitals, Anah General Hospital, Private hospitals at Al-Sulaimania Governorate (Gian private hospital). A total of 115 patients were included from March 2015 to December 2016, after prior informed consent. This study was committed after obtaining approval from the ethical committee of the Institutions.

Study Design:- Non randomized prospective study.

Inclusion criteria:- Patients with symptomatic gall stones.

Exclusion criteria:- Patients unfit for anesthesia, patient with acute cholecystitis and conversion to open due to equipment shortage

A preoperative score was given to every patient on the basis of history, clinical examination and sonological findings (Table 1), all surgeries were performed by the author,and have more than 14 years experience in the field of laparoscopic surgery.

Surgery was done using CO2 pneumoperitoneum with $13 \mathrm{mmHg}$ pressure, four ports $\{(2) 10 \mathrm{~mm},(2)$ $5 \mathrm{~mm}$. Time was noted from the $1^{\text {st }}$ port insertion to the last port closure.

All intraoperative events like duration of surgery, bile/stone spillage, and duct or artery injury were recorded and surgery was labeled as easy, difficult, and very difficult based on these findings (Table2).

Table 1:- Scoring factors used for grading patients parameters.

\begin{tabular}{|c|c|c|c|}
\hline \multicolumn{2}{|l|}{ History } & \multirow{2}{*}{$\frac{\text { Max. score }}{\mathbf{0}}$} & \multirow[b]{2}{*}{1} \\
\hline Age & $\leq \mathbf{5 0}$ & & \\
\hline & $>\mathbf{5 0}$ & 1 & \\
\hline \multirow[t]{2}{*}{ Sex } & Male & 1 & 1 \\
\hline & Female & $\mathbf{0}$ & \\
\hline \multirow[t]{2}{*}{ History of hospitalization for acute chole } & Yes & 4 & 4 \\
\hline & No & $\mathbf{0}$ & \\
\hline \multicolumn{4}{|l|}{ Clinical parameters } \\
\hline \multirow[t]{3}{*}{ BMI } & $<25$ & $\mathbf{0}$ & 2 \\
\hline & $25-27.5$ & 1 & \\
\hline & $>27.5$ & 2 & \\
\hline \multirow[t]{3}{*}{ Abdominal scar } & No & $\mathbf{0}$ & 1 \\
\hline & Infraumbilical & 1 & 1 \\
\hline & Supraumbilical & 2 & \\
\hline
\end{tabular}




\begin{tabular}{|c|c|c|c|}
\hline Palpable GB & Yes & $\mathbf{1}$ & 1 \\
\hline & No & $\mathbf{0}$ & \\
\hline Sonography & & $\mathbf{0}$ & 2 \\
\hline Wall thickness & $<\mathbf{4 m m}$ & $\mathbf{2}$ & 1 \\
\hline & $\mathbf{2 4 m m}$ & $\mathbf{0}$ & 1 \\
\hline Pericholecystic Fluid collection & No & $\mathbf{1}$ & \\
\hline Impacted stone & Yes & $\mathbf{0}$ & 1 \\
\hline & No & $\mathbf{1}$ & \\
\hline
\end{tabular}

Table 2:- Intraoperative assessment

\begin{tabular}{|c|c|c|}
\hline Parameters & Score & Grading \\
\hline Time $<60$ minutes and no bile spillage, no bile duct injury. & $0-5$ & Easy \\
\hline Time 60-120 minutes and/or bile or stone spillage or bile duct injury & $6-10$ & Difficult \\
\hline Time > 120 minutes or conversion to open & $11-15$ & Very difficult \\
\hline
\end{tabular}

The scores were compared in each patient to reach to a conclusion whether preoperative predictive score was a successful method or not .All statistical analysis were performed with a program statistical package for the social science 12.0 ( SPSS inc, Chicago, Illinois ). A p value of $\leq 0.05$ was accepted as statistically significant. Chi-square test/ Fisher exact test was used to find the significant association of findings of preoperative score with intraoperative outcome. Area under ROC was used to find the diagnostic and predictive value of preoperative score for predicting the intraoperative outcome.

\section{Results:-}

A total of 115 patients were included in this study. Majority of these patients were females (No. 103), (89.56\%). Following parameters were analyzed (table 3).

Table 3:- Distribution of parameters

\begin{tabular}{|c|c|c|}
\hline Patient characterstics $(\mathrm{n}=115)$ & $\mathbf{5 0}$ & Frequency \\
\hline Age & $\mathbf{5 0}$ & 28 \\
\hline Sex & Male & 12 \\
\hline & Female & 103 \\
\hline BMI & Yes & 36 \\
\hline & No & 79 \\
\hline History of hospitalization of acute cholecystitis & $<\mathbf{2 5}$ & 73 \\
\hline Abdominal scar & $\mathbf{2 5 - 2 7 . 5}$ & 9 \\
\hline & $\mathbf{2 2 7 . 5}$ & 33 \\
\hline Palpable gall bladder & Yes & 16 \\
\hline & No & 99 \\
\hline Thick wall gall bladder & Yes & 4 \\
\hline & No & 111 \\
\hline Pericholecystic fluid collection & Yes & 37 \\
\hline & No & 78 \\
\hline Impacted stone & Yes & 8 \\
\hline & No & 107 \\
\hline Yonersion to open cholecystectomy & Yes & 6 \\
\hline & & 109 \\
\hline & & None \\
\hline
\end{tabular}

Mean intraoperative time was (42 minutes) and (range 15-70 minutes). No cystic duct injury. Bile spillage was seen in 7 cases which were promptly managed with saline irrigation and suction. None of the cases needed conversion to open cholecystectomy. Postoperative hospital stay was $1 \pm 0.4$ days. Multivariate analysis of intraoperative outcome with risk factors were done which showed that the following factors (BMI > 27.5,history of hospitalization, 
palpable gall bladder, thick wall gall bladder and impacted stone) were statistically significant in preoperative prediction of difficult lap.chole (Table 4).

Table 4:- Multivariate analysis of intra-operative outcome with risk factors (predictive association of risk factors with intra-operative outcome)

\begin{tabular}{|c|c|c|c|c|}
\hline Risk factors & Level & Easy no. $(\%)$ & Difficult no (\%) & $\mathrm{P}$ value \\
\hline \multirow[t]{2}{*}{ Age } & $\leq 50$ & $83(72 \%)$ & $4(3.4 \%)$ & \\
\hline & $>50$ & $22(9 \%)$ & $6(5.2 \%)$ & $0.0132 * *$ \\
\hline \multirow[t]{2}{*}{ Sex } & Female & $93(80 \%)$ & $10(8.6 \%)$ & \\
\hline & Male & $9(7.8 \%)$ & $3(2.6 \%)$ & 0.113 \\
\hline \multirow[t]{3}{*}{ BMI } & $<25$ & $70(60.8 \%)$ & $3(2.6 \%)$ & \\
\hline & $25-27.5$ & $8(6.9 \%)$ & $1(0.86 \%)$ & $0.057 *$ \\
\hline & $>27.5$ & $27(23.4 \%)$ & $6(5.2 \%)$ & $0.001 * *$ \\
\hline \multirow[t]{2}{*}{ Abdominal scar } & No & $94(81.7 \%)$ & $3(2.6 \%)$ & \\
\hline & Yes & $14(12.1 \%)$ & $4(3.4 \%)$ & 0.063 \\
\hline \multirow[t]{2}{*}{ Hx of hospitalization } & No & $80(69.5 \%)$ & $3(2.6 \%)$ & \\
\hline & Yes & $27(23.4 \%)$ & $5(4.3 \%)$ & $0.0001 * * *$ \\
\hline \multirow[t]{2}{*}{ Palpable GB } & No & $107(93 \%)$ & $4(3.4 \%)$ & \\
\hline & Yes & $1(0.86 \%)$ & $3(2.6 \%)$ & $0.0001 * * *$ \\
\hline \multirow[t]{2}{*}{ Thick wall GB } & No & $81(70.4 \%)$ & $5(4.3 \%)$ & \\
\hline & Yes & $9(7.8 \%)$ & $20(17.3 \%)$ & $0.0001 * * *$ \\
\hline \multirow[t]{2}{*}{ Pericholecystic fluid collection } & No & $103(89.5 \%)$ & $4(3.4 \%)$ & \\
\hline & Yes & $5(4.3 \%)$ & $3(2.6 \%)$ & $0.001 * *$ \\
\hline \multirow[t]{2}{*}{ Impacted stone } & No & $98(85.2 \%)$ & $11(9.5 \%)$ & \\
\hline & Yes & $1(0.86 \%)$ & $5(4.3 \%)$ & $0.0001 * * *$ \\
\hline
\end{tabular}

*Moderately significant $0.01<\mathrm{p}<0.05$

$* *$ Strongly significant $\mathrm{p}<0.01$, highly significant if $\mathrm{p}<0.001$

At preoperative score of 5, sensitivity and specificity of this scoring method were $(96.78 \%)$ and $(83.45 \%)$ respectively. Positive predictive values of this scoring method were (93\%) and (91\%) for easy and difficult none of the patients had a score $>10$ (Table 5). Area under ROC curve was no conversion to open cholecystectomy (Fig. 1).

Table 5:- Correlation of preoperative score and the outcome.

\begin{tabular}{|c|c|c|c|c|}
\hline Preoperative score & Easy & Difficult & Very difficult & Total \\
\hline $0-5$ & $\mathbf{7 2}(62.6 \%)$ & $\mathbf{7 ( 6 . 0 8 \% )}$ & & $\mathbf{7 9}(\mathbf{6 8 . 6 \%})$ \\
\hline $\mathbf{6 - 1 0}$ & $\mathbf{1 7}(\mathbf{1 2 . 1 7 \%})$ & $\mathbf{1 9}(\mathbf{1 6 . 5 2 \%})$ & & $\mathbf{3 6 ( 3 1 . 3 \% )}$ \\
\hline T1-15 & None & & & \\
\hline Total & $\mathbf{8 9}(\mathbf{7 7 . 3 9})$ & $\mathbf{2 6}(\mathbf{2 2 . 6 0})$ & & \\
\hline
\end{tabular}




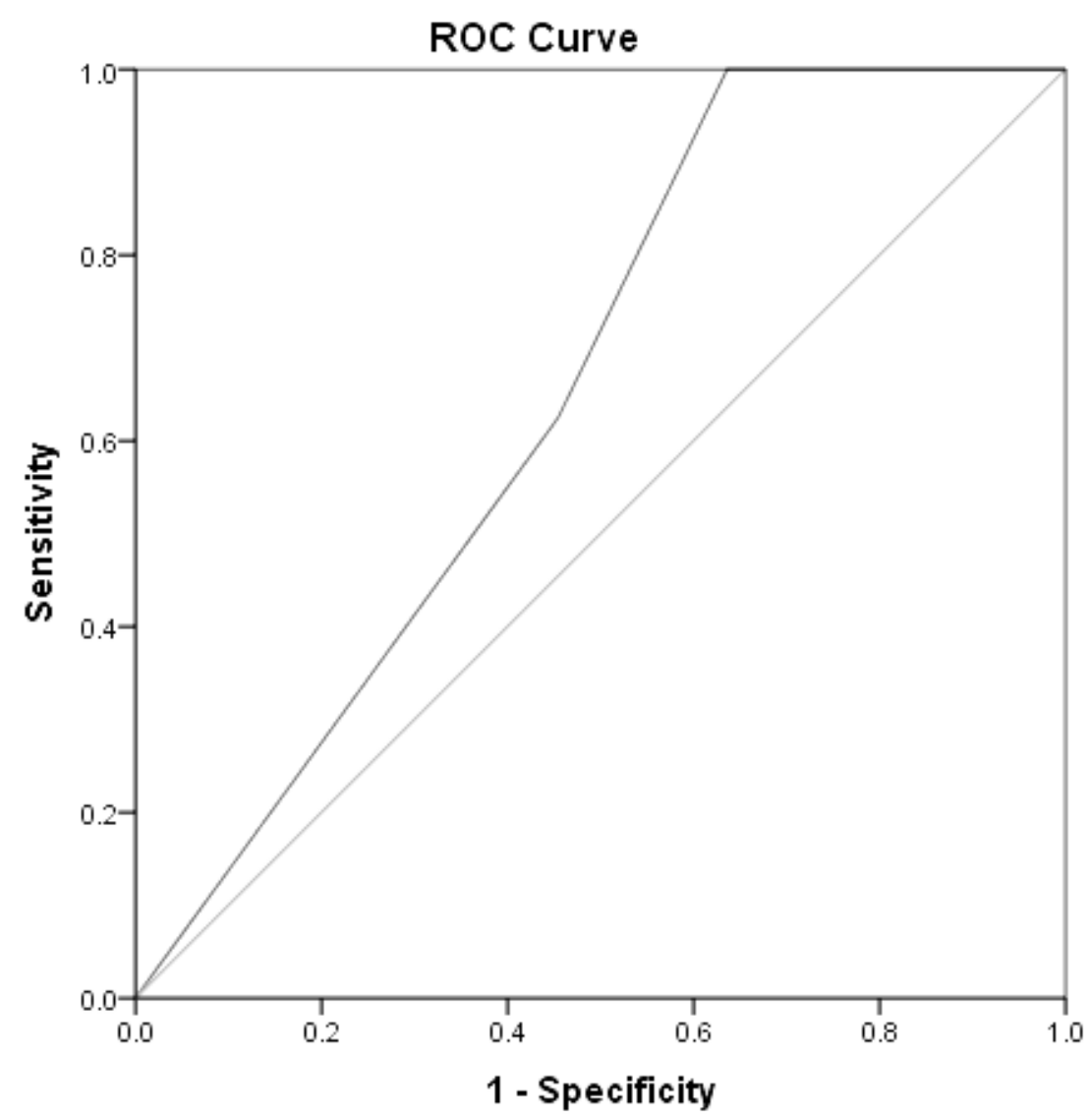

Fig 1:- ROC curve and the area under curve (0.653) of prediction of intraoperative outcome based on preoperative scores.

\section{Discussion:-}

Lap chole was $1^{\text {st }}$ performed in animal model by Fillipi, Mall and Roosma in 1985(8). Philip Mouret in1987 was the $1^{\text {st }}$ one to remove the gall bladder successfully through an- unmagnified mechanical rigid pipe without doing laparotomy.

Early, the complications rate of lap chole was high, but with technological advancement and expertise improvement it has now reached a remarkably low level at 20-60\%. (8) Conversion rate of $7.35 \%$ has been reported in literature (9).

In this study lap chole done for 115 patients and different predictive risk factors for difficult LC were analyzed. Old age, male sex, history of hospitalization, obesity, palpable GB and ultrasonographic findings like gall bladder wall thickness, pericholecystitic fluid collection, impacted stone were included as risk factors in this study.

Old age (> 50 years ) has been found to be a significant risk factor for difficult LC in many studies. $(10,11)$ Higher conversion rate had been reported in old age group of patients. In this study it was found as a significant factors ( $\mathrm{P}$ $0.0132)$.

Male sex makes surgery difficult as being reported in studies.(12,13) Conversion rate and significantly higher morbidity had been reported in male sex.13 In our study it has not been found as a significant factor ( $\mathrm{P} \quad 0.113$ ).

Patient require hospitalization for repeated attacks of acute cholecystitis Carry more chances of difficult LC and conversion, probably due to dense adhesions at Calot's triangle and GB fossa. $(14,15)$ In this study it was also found 
to be a significant risk factor for prediction of difficult LC ( P 0.0001 ), these cases required more time for dissection of Calot's triangle and GB dissection from liver bed ( $>40$ minutes).

Obesity has been encountered as a risk factor for difficult LC as observed by Rosen et al. (16) but certain studies claim that there was no difference in operative time, time to regain regular diet, duration of hospital stay or complications in obese patients (17) In this study BMI Patients > 27.5 ( P 0.001) significantly affect the outcome .

Previous upper or lower abdominal surgery may cause adhesions between viscera or omentum and abdominal wall, for this there may be chances of injury to these structures during insertion of $1^{\text {st }}$ port and the risk of conversion was reported to be higher.(18,19,20). In our study only (14) had infra-umbilical scar and (2) had supra-umbilical. It was not found to be a significant risk factor for difficult LC (P 0.063 ) may be because of small size sample.

Palpable GB is a clinical finding seen in patients with distended GB due to mucocele or empyema etc. In distended GB it is difficult to catch hold of the fundus of the GB and aspiration of GB contents is often required. It is bothering, time consuming and also there is a chance of contents spillage into the peritoneal cavity. There is only one study by Randhawa et al. (21) which has correlated palpable GB with intraoperative difficulty with a significant association. In this study (4) out of 115 patients had palpable GB. The outcome of our study was dependent on this variable (P 0.0001) and it has also been found to be a highly significant factor.

Thickened GB wall is an ultrasonic finding of acute cholecystitis and it was a significant factor in previous studies. (12, 22, 23). Majeski James (15) in 1990 showed that a preoperative GB ultrasonic evaluation for symptomatic cholelithiasis which document thickened GB wall $(3 \mathrm{~mm})$ with calculi, is a clinical warning for the laparoscopic surgeon of the potential for difficult LC. In this study thickened GB wall was present in (29) patients and outcome was found to be dependent on this variable by Chi-square test (P 0.001), and logistic regression analysis also ascertained the significance of this factor for prediction (P 0.05).

Pericholecystitic fluid is an ultrasonic finding of acute cholecystitis. (24) This was found to be a highly significant factor in our study (P 0.001). On the other hand impacted stone has been found as a significant factor in our study (P $0.001)$.

A scoring system was used in our study for prediction of difficult LC. Sensitivity and specificity of the scoring system at score 5 for prediction of easy or difficult lap chole are $(96.78 \%$ ) and ( $83.45 \%$ ) respectively. Area under ROC curve is (0.653). Prediction comes true in (93\%) for easy and (91\%) for difficult. Previous study on this scoring method has sensitivity and specificity of $75 \%$ and $90.24 \%$ respectively with positive predictive values for easy and difficult as $88.8 \%$ and $92.2 \%$ and area under ROC curve as 0.82 . So, in this study, this scoring system was found to be more sensitive than previous studies. However, a positive predictive value for difficult cases as less as compared to the findings published by Randhawa et al. (21). Conversion rate reported in literature was between 7 and $35 \%$ (25-31). In our study there was no conversion, partly because of the small size sample.

Undoubtedly surgeon experience and advanced equipment are integral factors in making LC an extremely safe procedure. In our study no injury encountered neither to artery nor to duct. Bile spillage was present in cases in our study; none of these cases were converted to open and were managed by irrigation and suction only.

\section{Conclusion:-}

We may conclude that the scoring system used and evaluated in our study is a useful and reliable benchmark to predict difficult cases. However, the small size may be an obstacle in attaining complete statistical validity. We suggest large scale, multicentric studies to validate the scoring methodology and establish its efficacy.

Ethical approval: Ethical committee of the institution. 


\section{References:-}

1. The southern surgeons club. A prospective analysis of 1518 laparoscopic holecystectomy. N Engl J Med.1991 Apr; 324 (16) : 1073-8.

2. Abdel Baki NA, Mutawei MA, Soliman KE, Farouk AM, Pre-operative prediction of difficult laparoscopic cholecystectomy using clinical and ultrasonographic parameters. J Med Res Inst.2006; 27 (3) : 102-7.

3. Cushieri A, Dubois, Mouiel J, Mouret P, Becker H, Buess G, et al. The European experience with laparoscopic cholecystectomy. Am J Surg. 1991 Mar; 161 (3): 385-7.

4. Kum CK, Goh PM, Isaac JR, Tekant Y, Ngot SS. Laparoscopic cholecystectomy for acute cholecystitis. $\mathrm{Br} J$ Surg.1994 Nov; 81(11):1651-4.

5. 5.Sikora SS, Kumar A, Saxena R, Kapoor K, Kaushik SP. Laparoscopic cholecystectomy, can conversion be predicted?. World J Surg. 1995 Nov-Dec; 19(6):858-60.

6. NA Kama, M. Kologlu, M. Doganay E, Reis M.AH, M. Dolapei. A risk scores for conversion from laparoscopic to ospen cholecystectomy. Am J Surg. Volume 181, 2001,pp.520-525.

7. N.W. Lee, J. Collins, R. Britt, L.D Britt. Evaluation of pre-operative risk factors for converting laparoscopic to open cholecystectomy. Am J Surg., 2012 Aug; 78(8): 831-833.

8. G.S Litynski, Eric Muhe and the rejection of laparoscopic cholecystectomy surgeons ahead of his time. JSLS. Volume 2, 1998. PP. 341-345.

9. I.A. Khan, O.E. El-Tiny. Laparoscopic cholecystectomy for acute cholecystitis, can pre-operative factors predict conversion. Saudi Med J .2004; 25(3):299-302.

10. Brunt LM, Quasebarth MA, Dunnegan DL, Soper NJ. Outcome and analysis of laparoscopic cholecystectomy in extremely elderly patients. Surg Endosc. 2001 Jul; 15(7): 700-5.

11. Nachnani J, Sope A. Pre-operatie prediction of difficult laparoscopic cholecystectomy using clinical and ultrasonographic parameters. Indian J Gastroenterol. 2005 Jan-Feb; 24(1): 16-8.

12. K. Singh, A. Ohri. Dpifficult laparoscopic: a large series from north India. Ind J Surg, 2006; 68(4) : 205-208. H.H Lein, C.S. Huang. Male gender: risk factors for severe symptomatic cholelithiasis. World J Surg. 2002; 26: 598-601.

13. L.Bouarfa,A. Shneider, H.Feussner, N. Narab, H.U Lemke, PP. Jonker, et al. Prediction of intraoperative complexity from preoperative patient data for laparoscopic cholecystectomy. Artif Intell Med. 2011 Jul; 52(3): 169-176.

14. J. Majeski. Significance of pre-operative ultrasonic measurement of gallbladder wall thickness. Am J Surg. 2007; 73(9) : 926-929.

15. M. Rosen, F. Brody, J. Ponsky. Predictive factors for conversion of laparoscopic cholecystectomy. Am J Surg.2003; 184(3):254-258.

16. C. Simopoulos, A. Polychronidis, S. Botaitis, S. Perente, M. Pitiakoudis. Laparoscopic cholecystectomy in obese patients. Obes Surg. 2005; 15(2) :243-246.

17. A. Hussien. Difficult laparoscopic cholecystectomy, current evidence and stratigies of management. sSurg Laparosc Endosc Percut Tech. 2011; 21(4) : 211-217.

18. Hutchinson GH, Traverso LW, Lee FT. Laparoscopic cholecystectomy: Do pre-operative factors predict the need to convert to open surgery ? Surg Endosc. 1994 Aug; 8(8):875-878.

19. Ibrahim S., Hean TK, Ho LS, Ravin-Tharan T, Chue TN, Chee CH. Risk factors for conversion to open surgery in patient undergoing laparoscopic cholecystectomy. World J Surg. 2006 Sep; 30(9):1698-1704.

20. S. Randhawa, A.K. Pujahari. Preoperative prediction of difficult laparoscopic cholecystectomy: A scoring method. Indian J Surg. 2009: 71: 198-201.

21. S.S Daradkeh, Z.Suwan, M. Abu-Khakaf. Preoperative ultrasound and prediction of difficulties in laparoscopic cholecystectomy. World J Surg.1998; 22:75-77.

22. E. Carmody, A.M. Arenson, S. Hanna. Failed or difficult laparoscopic cholecystectomy : can pre-operative ultrasound identify potential problems. J Clin Ultrasound .1994;22(6): 391-396.

23. Jansen S, Jorgensen J, Caplehorn J, Hunt D. Pre-operative ultrasound to predict conversion in laparoscopic cholecystectomy . Surg Laparosc Endosc .1997 Apr ; 7(2): 121-123.

24. Bakos E, Bakos M, Dubaj M, Prekop J, Jankovic T. Conversion in laparoscopic cholecystectomy. Bartisl Lek Listy.2008; 109(7):317-319.

25. Ishizaki Y, Miwa K, Yoshimoto J, Sugo H, Kawasaki S. Conversion of elective laparoscopic to open cholecystectomy between and 2004. Br J Surg.2006 Aug; 93(8): 987-991.

26. Gholipour C, Fakhree MB, Shachi RA, Abbasi M. Prediction of conversion of laparoscopic cholecystectomyto open surgery with artificial neural network. BMC Surg. 2009 Aug; 9:13. 
27. Memon W, Khamzada TW, Samad A, Laaghari MH. Laparoscopic cholecystectomy: Conversion rate and its causes at Isra University hospital, Hyderabad. Rawal Med J.2008; 33:159-161.

28. Livingstone EH, Rege RV. A nationwide study of conversion from laparoscopic to open cholecystectomy. Am J Surg.2004 Sep;188(3): 205-211.

29. Peters JH, Krailadsiri W, Incarbone R, Bremner CG, Froes E, Ireland AP, et al. Reasons for conversion from laparoscopic to open cholecystectomy in an urban teaching hospital. Am J Surg.1994 Dec; 168 (6): 555-558.

30. Lo CM, Fan ST, Liu CL, Lai CS, Wong J. Early decision for conversion from laparoscopic to open cholecystectomy for the treatment of acute cholecystitis. Am J Surg. 1997 Jun; 173 (6): 513-517. 